\title{
Psychological disorders after coronary artery by-pass surgery: a one-year prospective study
}

\section{Disordini psicologici dopo bypass aorto-cronarico: studio prospettico ad un anno}

\author{
Rosa Spezzaferri, Maddalena Modica, Vittorio Racca, Vittorino Ripamonti, \\ Monica Tavanelli, Gabriella Brambilla, Maurizio Ferratini
}

\begin{abstract}
Psychological disorders after coronary artery by-pass surgery: a one-year prospective study. R. Spezzaferri, M. Modica, V. Racca, V. Ripamonti, M. Tavanelli, G. Brambilla, M. Ferratini.

Background: Coronary artery by-pass surgery (CABG) is often followed by anxiety and depression that require early identification in order to provide adequate psychological support. The predictive role of tests administered soon after CABG on long-term psychological outcomes has been only incompletely explored.

Aim, Design and Methods: Aim of this study was to assess post-operative and 12-month persistence of psychological disorders by means of the Minnesota Multiphasic Personality Inventory (MMPI-2) and the depression and state and trait anxiety scales of the Cognitive Behavioural Assessment (CBA-2.0) in 118 male patients admitted to cardiac rehabilitation after CABG.

Results: Early after CABG we observed a high preva-
\end{abstract} lence of depression ( $11.8 \%$ by MMPI-2 and $12.7 \%$ by CBA) and state anxiety (23.5\%). At 1-year the MMPI-2 scale D indicated stable mean score and high scores at entry were predictive of persistent depression. Conversely the CBA-2.0 scale QD score significantly decreased (from $3.86 \pm 3.19$ to 2.91 \pm 3.45 , $p=0.017$ ). Also $S T 1$ state anxiety significantly decreased (from $35.17 \pm 6.95$ to $32.55 \pm 6.72, p=0.003$ ) whereas ST2 trait anxiety was stable. We found no association between psychometric results and ventricular function, number of grafts or time since diagnosis of coronary artery disease.

Conclusions: State anxiety and depression by CBA significantly decreased 1-year after CABG; conversely trait anxiety and depression, investigated by MMPI-2, a more specific personality questionnaire, were stable. High scores for the depression in the scale D of MMPI-2 early after CABG seem to be predictive of the persistence of the disorder at 1-year.

Keywords: anxiety, coronary artery by-pass surgery, depression, psychological disorders.

Monaldi Arch Chest Dis 2009; 72: 200-205.

Unità Operativa di Cardiologia Riabilitativa, Centro IRCCS “Santa Maria Nascente”, Fondazione Don Carlo Gnocchi ONLUS, Milan, Italy.

Corresponding author: Dott. Vittorio Racca; Fondazione Don Carlo Gnocchi, Istituto S. Maria Nascente; Via Capecelatro 66, I-20148 Milano MI, Italia; E-mail address:vracca@dongnocchi.it

\section{Introduction}

Depression and anxiety have both been recognised as independent risk factors for the development of coronary artery disease (CAD) [1-5], and psychologically distressed subjects affected by CAD have a poorer quality of life, and higher morbidity and mortality rates [6-8].

Coronary artery by-pass surgery $(\mathrm{CABG})$ is a major stressful event that is often followed by anxiety and depression [9-11]. Early identification of such post-CABG disorders is important in order to provide adequate treatment and improve psychological assistance and clinical outcomes [12-15] and many validated questionnaires have been used to explore psychological disorders in this setting. The evaluation of psychological profiles after a traumatic event such as cardiac surgery is complicated by the overlap of physical and psychological symptoms, and patients' frailty [16-23].

Type A behaviour has been established in the past, since 1981, as a possible risk factor of CAD in industrialized countries [24]; further research has produced both contrary and inconsistent findings regarding this association [25]; the relation of behavioural and psychosocial factors to the morbidity and mortality of coronary heart disease (CHD) is still debated.

Gender differences in the incidence of depression and anxiety should be addressed as possible confounding factors [26]. The role of the tests administered soon after CABG as predictors of long-term psychological outcomes has been only incompletely explored [10-15].

Aim of this study was to investigate with exhaustive questionnaires 1-year psychological outcomes in a homogeneous population of 118 male Caucasian patients who had undergone $\mathrm{CABG}$, and to assess the value of early postoperative tests in predicting them.

Methods

All recruited patients had been consecutively admitted to our Rehabilitation Unit for a 20-day period 
of cardiac rehabilitation. Exclusion criteria were a history of psychological-psychiatric disturbances, and the presence of factors preventing the completion of the questionnaires, such as inadequate command of the Italian language, cognitive impairment and visual deficits. Furthermore we elected to enrol only male patients, in view of the different genderrelated incidence in psychological disturbances after CABG. None of the subjects was on psychoactive drugs at the time of enrolment, and all of them gave their informed consent. Patients' educational level was classified as primary, middle or high school, or university. A clinical check-up was performed after 1 year. Our Institutional Review Board approved the study.

Psychometric and cardiac evaluations were performed early in the postoperative period, $(10 \pm 2$ days) and repeated after one year.

Cardiac evaluation at baseline and at the end of the follow-up period included demographic characteristics, New York Heart Association (NYHA) functional class, left ventricular ejection fraction (LVEF) as determined by color Doppler ultrasonography, history and duration of CAD (more or less than 12 months), number of coronary by-pass grafts, clinical events, and pharmacological regimen.

Psychological evaluation has been performed using the complete version of the Minnesota Multiphasic Personality Inventory-2 (MMPI-2) and the Cognitive Behavioural Assessment (CBA-2.0), both translated in Italian language. The MMPI-2 is a validated instrument for assessment of adult psychopathology, widely used by clinicians to assist with the diagnosis of mental disorders and the selection of appropriate treatment [17]. The instrument includes 567 true/false items and clinical, content and supplementary scales. A score more than 65 was considered abnormal. Among clinical subscales the scale D (depression) includes 57 items exploring personality aspects of depression as excess of sense of duty, high personal standards and intrapunitivity. Elevated scores on this scale may suggest clinical symptomatic depression or an attitude characterized by depressed mood as can be observed in patients after a traumatic injury event. For this reason it may result as one of the least stable trait of personality [18].

The CBA-2.0 is a self-administered psychometric instrument; we used STAI-X1 scale to test state anxiety, a transitorily emotional status that varies in intensity depending on the circumstances (cut off score >39.5). The STAI-X2 scale was used to test trait anxiety, a more stable personality condition, characterizing the patient on an ongoing, independently by a particular situation (cut off score >43) and the CBA-QD scale was used to test depression and evaluates both somatic symptoms, such as sleep disturbances, loss of appetite, tiredness and fatigue, and psychological symptoms, such as difficulties in concentration (cut off score for depression >7.3).

\section{Statistical analysis}

Continuous variables, expressed as mean values \pm standard deviation (SD), were compared by Student's paired or unpaired, where appropriate, t test. Discrete variables, expressed as absolute or relative percentages, and dichotomically related samples were compared by McNemar's test. The univariate relationships between clinical variables, depression, state and trait anxiety were evaluated using the chisquare test. A p value of $<0.05$ was considered statistically significant.

Data were analysed using SPSS version 13.0 software (SPSS Inc., Chicago, IL, USA).

\section{Results}

\section{Clinical characteristics}

We report the results for 93 (78.8\%) of the 118 enrolled patients with 1-year follow-up data available: eight patients refused to continue the study, one died of complicated pneumonia, sixteen patients were excluded for standard invalidity criteria of MMPI-2: "cannot say" scale >30, scale L (lie), F (infrequency) $>65, \mathrm{~K}$ (correction) $>65$.

Mean age of the completers was $63.5 \pm 7.7$ years. In terms of education, $19.3 \%$ had only attended primary school, whereas $24.7 \%$ had also attended middle school, $43.2 \%$ high school, and $12.8 \%$ university.

Patients were mostly in NYHA functional class I or II $(97.8 \%)$. Mean LVEF was $54.9 \pm 10 \%$ at enrolment and $56.1 \pm 8.9 \%$ at the end of the year. Duration of CAD averaged $64 \pm 85$ months, but $38.7 \%$ of the patients had a less than one year history of disease. Coronary grafts were one in $8.6 \%$ of the patients, two in $22.6 \%$, three in $43 \%$, and four or more in $25.8 \%$. Details of administered medications at baseline and at one year (Table 1) document a significant improvement in the prescription rate of recommended treatments.

\section{Psychometric evaluation}

Prevalence of depression and anxiety at baseline and follow-up are shown in Table 2. Mean values of scores upon repeated psychometric testing are shown in Tables 3.

\begin{tabular}{|c|c|c|c|}
\hline & baseline & 1-year & $\mathbf{p}$ \\
\hline Beta-blockers & 80.7 & 84.3 & 0.494 \\
\hline Aspirin & 84.4 & 97.1 & 0.007 \\
\hline Ace-inhibitors & 46.3 & 65.7 & 0.050 \\
\hline Statines & 55.0 & 68.6 & 0.048 \\
\hline
\end{tabular}

Table 2. - Prevalence of psychopathological syndromes (percentage of patients above cut-off)

\begin{tabular}{lccc}
\hline Scales & Baseline & Follow-up & p \\
\hline D MMPI-2 & $12(11.8 \%)$ & $16(15.7 \%)$ & 0.424 \\
CBA-QD (depression) & $13(12.7 \%)$ & $6(5.9 \%)$ & 0.092 \\
ST1 (state anxiety) & $24(23.5 \%)$ & $11(10.8 \%)$ & 0.011 \\
ST2 (trait anxiety) & $7(6.9 \%)$ & $8(7.8 \%)$ & 1.0 \\
\hline
\end{tabular}

$\mathrm{CBA}=$ Cognitive Behavioural Assessment MMPI-2= Minnesota Multiphasic Personality Inventory-2 
Table 3. - Mean and standard deviation of CBA-2.0 and MMPI-2 scores

\begin{tabular}{|c|c|c|c|}
\hline & Baseline & Follow-up & \\
\hline CBA-QD (depression) & $3.86 \pm 3.19$ & $2.91 \pm 3.45$ & $0.017^{*}$ \\
\hline ST1 (state anxiety) & $35.17 \pm 6.95$ & $32.55 \pm 6.72$ & $0.003^{*}$ \\
\hline ST2 (trait anxiety) & $32.17 \pm 8.26$ & $31.76 \pm 8.24$ & 0.631 \\
\hline \multicolumn{4}{|l|}{ MMPI-2 Clinical Scales } \\
\hline HS Hypochondriasis & $55.98 \pm 11.70$ & $55.41 \pm 9.58$ & 0.614 \\
\hline D Depression & $53.90 \pm 10.21$ & $54.10 \pm 10.06$ & 0.817 \\
\hline HY Hysteria & $49.37 \pm 9.10$ & $48.13 \pm 8.46$ & 0.115 \\
\hline PD Psychopatic Deviation & $45.86 \pm 8.84$ & $45.39 \pm 8.49$ & 0.567 \\
\hline PA Paranoia & $46.45 \pm 8.02$ & $46.67 \pm 8.48$ & 0.804 \\
\hline PT Psychasthenia & $46.45 \pm 8.55$ & $45.58 \pm 8.65$ & 0.284 \\
\hline SC Schizophrenia & $47.94 \pm 9.16$ & $46.58 \pm 8.22$ & 0.081 \\
\hline MA Hypomania & $44.90 \pm 8.46$ & $43.80 \pm 8.06$ & 0.139 \\
\hline SI Social Introversion & $55.15 \pm 8.10$ & $53.48 \pm 8.63$ & $0.005^{*}$ \\
\hline \multicolumn{4}{|l|}{ Content Scales } \\
\hline ANX Anxiety & $52.28 \pm 7.93$ & $50.94 \pm 8.93$ & 0.062 \\
\hline FRS Fears & $52.95 \pm 8.23$ & $52.76 \pm 8.85$ & 0.808 \\
\hline OBS Obsessiveness & $50.48 \pm 7.02$ & $50.17 \pm 7.11$ & 0.613 \\
\hline DEP Depression & $49.72 \pm 8.33$ & $50.02 \pm 9.65$ & 0.663 \\
\hline HEA Health Concerns & $55.78 \pm 8.58$ & $55.12 \pm 7.96$ & 0.356 \\
\hline BIZ Bizarre Mentation & $50.87 \pm 8.41$ & $49.40 \pm 8.73$ & $0.046^{*}$ \\
\hline ANG Anger & $49.77 \pm 6.86$ & $49.87 \pm 6.93$ & 0.886 \\
\hline CYN Cynism & $54.45 \pm 9.5$ & $55.30 \pm 10.84$ & 0.268 \\
\hline ASP Antisocial Practices & $51.65 \pm 9.90$ & $51.20 \pm 9.23$ & 0.538 \\
\hline TPA Type A & $52.55 \pm 8.62$ & $52.86 \pm 9.04$ & 0.672 \\
\hline LSE Low Self-Esteem & $51.54 \pm 7.49$ & $51.34 \pm 7.70$ & 0.775 \\
\hline SOD Social Discomfort & $54.82 \pm 8.46$ & $53.95 \pm 8.69$ & 0.201 \\
\hline FAM Family Problems & $48.04 \pm 7.18$ & $48.00 \pm 7.93$ & 0.950 \\
\hline WRT Work Interference & $49.89 \pm 7.38$ & $49.96 \pm 7.72$ & 0.904 \\
\hline TRT Negative Treatment & $53.67 \pm 8.38$ & $53.34 \pm 9.24$ & 0.668 \\
\hline \multicolumn{4}{|l|}{ Supplementary Scales } \\
\hline PK Post-traumatic stress disorders & $48.59 \pm 6.96$ & $48.42 \pm 7.68$ & 0.716 \\
\hline OH Hostility & $48.99 \pm 9.04$ & $48.58 \pm 9.45$ & 0.671 \\
\hline A Anxiety & $49.00 \pm 7.24$ & $49.38 \pm 7.66$ & 0.476 \\
\hline R Repression & $52.24 \pm 10.57$ & $51.59 \pm 10.26$ & 0.465 \\
\hline PS Post-traumatic stress disorders & $49.59 \pm 7.08$ & $49.11 \pm 7.62$ & 0.354 \\
\hline MDS Marital Distress & $45.68 \pm 6.79$ & $45.86 \pm 7.34$ & 0.780 \\
\hline
\end{tabular}

Mc Nemar's test, $p<.005$
At MMPI-2 twelve patients (11.8\%) scored above cut-off values at baseline. Depression persisted at one year in seven patients, while nine patients below cut-off values at baseline developed depression at follow-up. Persistently depressed patients scored on average higher than patients in whom depression disappeared at the end of followup (74.0 vs 68.4 p=0.05) as shown in Table 4, suggesting that high basal values may be considered predictors of the outcome of depression.

The CBA-2.0 QD scale was consistent with depression in 13 subjects at baseline and 6 at 1year follow-up, showing a nonsignificant trend to decrease $(\mathrm{p}=$ 0.092). The trend to improvement was confirmed by the significant decrement in average scores. The proportion of subjects who scored above cutoff for state anxiety decreased significantly from baseline to follow-up (Table 2), as well as the average ST1 scores (Table 3 ). Conversely, the percentage of patients above threshold for trait anxiety was lower and, as expected, stable through follow-up, with no significant changes at 1year assessment in ST2 (trait anxiety) scores. When the scores were stratified according to age, we didn't observe any relevant differences compared to the Italian sample except for higher score of depression in the subgroup of patients aged 60-70 years [18].

None of the above results was significantly affected by the subjects' educational level stratified as primary, middle, high school or university.

By univariate analysis 1year depression in both scales, state and trait anxiety by CBA

At the MMPI-2 scale score analysis (Table 3), only social introversion and bizarre mentation scales showed significant changes versus baseline. Conversely, depression score, trauma scale score and the mean score of subjects with a type A personality were unchanged at the end of the study.

In the clinical scales the mean values of the scores were significantly higher than the reference Italian population for hypochondria, depression, psychopathic deviation, social introversion and in the content scales for anxiety, fears, obsessiveness, health concern, bizarre mentation, cynicism, antisocial practices, type A personality, low self-esteem, social discomfort, negative treatment [17]. were not significantly associated to the severity of cardiac disease expressed in terms of left ventricular function, time elapsed since diagnosis of CAD, or the number of venous and/or arterial grafts received (Table 5).

\section{Adverse events}

During the 12 months of follow-up, cardiac events were observed in $9.2 \%$ of the patients: five had residual effort angina, two developed heart failure requiring hospital admission, two had atrial fibrillation, and one sustained premature ventricular beats. Minor vascular complications were observed in $7.3 \%$, while one patient died of pneumonia. Mi- 
Table 4. - Patients above cut-off and mean scores

\begin{tabular}{|c|c|c|c|c|}
\hline & \multicolumn{2}{|c|}{ Baseline } & \multicolumn{2}{|c|}{ Follow-up } \\
\hline & $N$ & Mean score & $N$. & Mean score \\
\hline D MMPI-2 & 12 & 71.7 & 16 & 70.1 \\
\hline $\mathbf{A}$ & 7 & $74.0(*)$ & 7 & 70.4 \\
\hline B & 5 & $68.4(*)$ & 9 & 69.9 \\
\hline D CBA-2.0 & 13 & 10.0 & 6 & 13.0 \\
\hline $\mathbf{A}$ & 3 & 9.3 & 3 & 11.0 \\
\hline B & 10 & 10.2 & 3 & 15.0 \\
\hline ST1 CBA-2.0 & 24 & 45.3 & 11 & 45.7 \\
\hline $\mathbf{A}$ & 6 & 44.8 & 6 & 45.2 \\
\hline B & 18 & 45.4 & 5 & 44.8 \\
\hline ST2 CBA-2.0 & 7 & 50.7 & 8 & 51.0 \\
\hline $\mathbf{A}$ & 3 & 50.7 & 3 & 51.7 \\
\hline B & 4 & 50.7 & 5 & 50.6 \\
\hline
\end{tabular}

nor internal medicine complications not requiring hospitalisation occurred in $21.1 \%$ of the patients.

\section{Discussion}

Psychological and cardiac disease-related symptoms overlap in patients undergoing $\mathrm{CABG}$, thus making psychodiagnosis more difficult $[27,28]$. For the purposes of this study, we administered a complex set of psychometric questionnaires, including the very sensitive 567-item MMPI-2, which obviously cannot be routinely used in clinical cardiology practice.
We elected to include only male patients in order to avoid the well-known confounding effects of gender [26].

We found no significant association between psychometric results and clinical variables.

Among male CAD patients, early after $\mathrm{CABG}$, we observed a high prevalence of depression; at 1 year we registered a significant decrease in CBA-QD scores but not in Depression scale of MMPI-2. The proportion of depressed patients in both scales early after surgery was higher than the $5-10 \%$ prevalence recorded in community-based epidemiological studies [29]. The different performance of the CBA-QD, which showed a decrease in both proportion of affected subjects and average scores, and the MMPI- 2 scale D, where we did not find any significant change, can be attributed to the different construction of the two tests. In fact MMPI-2 is mainly focused on personality aspects, whereas CBA2 also includes somatic symptoms.

High basal scores for depression by MMPI-2 scale D seem predictive of the persistence of the disorder at 1-year (Table 5), suggesting that psychological intervention should be more prolonged in the subjects with higher baseline scores.

State and trait anxiety were investigated using the STAI-X1 and STAI-X2 scales. State anxiety decreased significantly after one year, and disappeared in 13 patients: this relevant finding can be expected after a successful major therapeutic intervention such as cardiac surgery. However the overlap in average baseline scores between patients who showed sustained anxiety and in those who did not score above cut-off in this scale at follow-up (Table 4) suggests that scores in state anxiety are not predictive of the eventual persistence of this psychological disturbance in the long term.

Conversely the prevalence of trait anxiety did not change at 1 year. Published long-term studies of adequate samples of CABG patients affected by trait anxiety are scarce.

Table 5. - Univariate relation between depression, state and trait anxiety and clinical variables

\begin{tabular}{|c|c|c|c|c|c|c|c|c|}
\hline & \multicolumn{2}{|c|}{ Scale D MMPI-2 } & \multicolumn{2}{|c|}{ Depression CBA } & \multicolumn{2}{|c|}{ State anxiety } & \multicolumn{2}{|c|}{ Trait Anxiety } \\
\hline & + & - & + & - & + & - & + & - \\
\hline LVEF $<45 \%$ & $15.4 \%$ & $84.6 \%$ & $7.7 \%$ & $92.3 \%$ & $30.8 \%$ & $69.2 \%$ & $0.0 \%$ & $100 \%$ \\
\hline LVEF $\geq 45 \%$ & $12.5 \%$ & $87.5 \%$ & $15.0 \%$ & $85.0 \%$ & $25.0 \%$ & $75.0 \%$ & $8.8 \%$ & $91.3 \%$ \\
\hline $\mathbf{p}$ & \multicolumn{2}{|c|}{0.673} & \multicolumn{2}{|c|}{0.685} & \multicolumn{2}{|c|}{0.735} & \multicolumn{2}{|c|}{0.588} \\
\hline N.grafts $\leq 2$ & $17.2 \%$ & $82.8 \%$ & $3.4 \%$ & $96.6 \%$ & $24.1 \%$ & $75.9 \%$ & $0.0 \%$ & $100 \%$ \\
\hline N.grafts $>2$ & $10.9 \%$ & $89.1 \%$ & $18.8 \%$ & $81.3 \%$ & $26.6 \%$ & $73.4 \%$ & $10.9 \%$ & $89.1 \%$ \\
\hline $\mathbf{p}$ & \multicolumn{2}{|c|}{0.506} & \multicolumn{2}{|c|}{0.057} & \multicolumn{2}{|c|}{1.0} & \multicolumn{2}{|c|}{0.094} \\
\hline CAD $<12$ months & $7.8 \%$ & $92.2 \%$ & $15.7 \%$ & $84.3 \%$ & $23.5 \%$ & $76.5 \%$ & $7.8 \%$ & $92.2 \%$ \\
\hline CAD $\geq 12$ months & $19 \%$ & $81 \%$ & $11.9 \%$ & $88.1 \%$ & $28.6 \%$ & $71.4 \%$ & $7.1 \%$ & $92.9 \%$ \\
\hline $\mathbf{p}$ & \multicolumn{2}{|c|}{0.130} & \multicolumn{2}{|c|}{0.766} & \multicolumn{2}{|c|}{0.638} & \multicolumn{2}{|c|}{1.0} \\
\hline $\begin{array}{l}\text { Value expressed in } \\
\text { LVEF: Left ventric } \\
\text { N.grafts: Number } \\
\text { CAD: Time since }\end{array}$ & $\begin{array}{l}\text { on fracti } \\
\text { and/or ar } \\
\text { months) }\end{array}$ & $\begin{array}{l}\text { lal grafts } \\
\text { coronar }\end{array}$ & $\begin{array}{l}\text { ned at su } \\
\text { disease }\end{array}$ & & & & & \\
\hline
\end{tabular}


As far as the small number of enrolled patients allows affirming, the lack of significant changes at follow-up was expected, as the administered questionnaire explores anxiety especially as a subjective personality trait. However, unlike state anxiety, whose negative consequences have been reported by some authors, trait anxiety does not seem to be prognostically relevant $[27,30]$.

Analysis of the other MMPI-2 clinical, content and supplementary scales at enrollment and after one year revealed no significant differences, besides a significant decrease in the social introversion and bizarre mentation scale. The finding in many scales of average scores higher than in the reference Italian population and the lack of significant variation at follow-up indicate the persistence in our series of a complex psychopathological state that cannot be linked only to depression and/or anxiety. The 1-year persistence of high cynicism and hostility scores is relevant, because these psychopathological disorders are predictive of cardiac and total mortality [31].

Conversely the unexpected finding of similar average CBA scores in CABG patients and the reference Italian sample is probably linked to the setting where the questionnaires have been administered. The particular attention paid to patient reassurance in cardiological rehabilitation might have contained emotional aspects enough to lower the average scores of our sample.

The high percentages of patients taking drugs for secondary CAD prevention at enrolment and after one year indicate good compliance, which may be attributed to the particular perfectionist attitude and family support that characterise CAD patients.

Not all patients undergoing CABG usually attend cardiac rehabilitation; anyway it is important to underline that in our country there is not a financial charge for attendance and this eliminates a possible source of bias in patients' enrollment.

Our study is underpowered to evaluate the impact of psychological disorders on clinical outcomes, but the quantitatively relevant occurrence of adverse events demonstrates that subjects after CABG must be considered as fragile patients. A continuous psychological program in the management of these subjects could contribute to reduce the risk of adverse events and their impact on quality of life. From this point of view, one limitation of the study is the absence of structured psychological assistance during follow-up.

\section{Conclusions}

In this study we documented that 1 year after coronary surgery state anxiety and depression, psychopathological disorders linked to the surgical procedure significantly decreased, probably reflecting, besides the elapsed time since the acute event, the benefits of early psychological and rehabilitative interventions. On the contrary, trait anxiety and depression as diagnosed by MMPI- 2 scale $\mathrm{D}$, variables more related personality traits, were unchanged at follow-up. These findings were not related either to the education level or to severity and/or duration of CAD.

High basal scores for depression by MMPI-2 scale D seem predictive of the persistence of the disorder at 1-year, suggesting that the psychological intervention should be more prolonged in the subjects with higher baseline scores.

The finding of other important psychological abnormalities in MMPI-2 underscores the importance of considering the personologic complexity of each subject besides anxiety and depression. The identification of less complex, yet diagnostically accurate, psychometric tests than MMPI-2 for use in routine clinical practice is a continuing challenge for psychologists.

\section{Riassunto}

Introduzione: Dopo intervento di by pass coronarico $(C A B G)$ è frequente il riscontro di ansia e depressione; il loro riconoscimento precoce è importante al fine di fornire adeguato supporto psicologico. Non è ancora noto se i risultati dei questionari psicologici in fase precoce post-operatoria siano predittori dei disturbi psicologici a distanza.

Scopo, Disegno dello studio e Metodi: Lo scopo dello studio è stato di valutare in 118 soggetti maschi ricoverati presso l'Unità Operativa di Riabilitazione Cardiologica, la presenza di disturbi psicologici dopo CABG in fase precoce e dopo 12 mesi, mediante la somministrazione del Minnesota Multiphasic Personality Inventory (MMPI-2) ed in particolare la presenza di depressione ed ansia nelle sue componenti di stato e di tratto mediante il Cognitive Behavioural Assessment (CBA-2.0).

Risultati: In fase precoce dopo CABG abbiamo osservato un'elevata prevalenza di depressione (11.8\% con impiego di MMPI-2 e $12.7 \%$ con CBA) e di ansia di stato (23.5\%). Dopo un anno la scala D del MMPI-2 ha indicato stabilità dei valori medi; elevati punteggi all'entrata nello studio sono risultati essere predittivi di depressione persistente. Il punteggio della scala $Q D$ del CBA-2.0 è diminuito significativamente (da 3.86 \pm 3.19 a 2.91 \pm 3.45 , $p=0.017$ ). Inoltre è significativamente diminuita l'ansia di stato ST1 (da 35.17 \pm 6.95 a 32.55 $\pm 6.72, p=0.003$ ), mentre l'ansia di tratto ST2 è risultata stabile. Non abbiamo trovato associazione tra $i$ risultati psicometrici e la funzione ventricolare sinistra, il numero di by pass aorto-coronarici eseguiti ed il tempo intercorso dalla prima diagnosi di malattia coronarica.

Conclusioni: L'ansia di stato e la depressione si riducono significativamente un anno dopo by pass aorto-coronarico; per contro l'ansia di tratto e la depressione studiati con MMPI-2, un questionario più rivolto ad indagare le caratteristiche personologiche, rimangono sostanzialmente invariate. Elevati punteggi per la depressione (nella scala D del MMPI-2) sembrano predittivi della persistenza della depressione stessa a distanza.

\section{ACRONYMS}

$\mathrm{CAD}=$ Coronary Artery Disease

$\mathrm{CABG}=$ Coronary artery by-pass surgery

$\mathrm{CHD}=$ Coronary Heart Disease

NYHA = New York Heart Association

$\mathrm{LVEF}=$ left ventricular ejection fraction

MMPI-2= Minnesota Multiphasic Personality Inventory-2

CBA-2.0 $=$ Cognitive Behavioural Assessment

STAI $=$ State-Trait Anxiety Inventory

$\mathrm{SD}=$ standard deviation 


\section{References}

1. Rozanski A, Blumental JA, Kaplan J. Impact of psychological factor on the pathogenesis of cardiovascular disease and implication for therapy. Circulation 1999; 99: 2192-217.

2. Zellweger MJ, Osterwalder RH, Langewitz W, Pfisterer ME. Coronary artery disease and depression. Eur Heart $J$ 2004; 25: 3-9.

3. Todaro JF, Shen BJ, Niaura R, Spiro A. Effect of negative emotions on frequency of coronary heart disease (The Normative Aging Study). Am J Cardiol 2003; 92: 901-906.

4. Ariyo A, Hann M, Tangen CM, et al. Depressive symptoms and risks of coronary heart disease and mortality in elderly americans. Circulation 2000; 102: 1773-1779.

5. Whooley MA. Depression and cardiovascular disease. healing the broken-hearted. JAMA 2006; 295: 2874-2881.

6. Denollet J, Sys SU, Stroobant N, Rombouts H, Gillebert TC, Brutsaert DL. Personality as independent predictor of long-term mortality in patients with coronary heart disease. Lancet 1996; 347: 417-421.

7. Strik JJ, Denollet J, Lousberg R, Honig A. Comparing symptoms of depression and anxiety as predictors of cardiac events and increased health care consumption after myocardial infarction. J Am Coll Cardiol 2003; 42: 1801-1807.

8. Nicholson A, Kuper H, Hemingway H. Depression as an aetiologic and prognostic factor in coronary heart disease: a meta-analysis of 6362 events among 146538 partecipants in 54 observational studies. Eur Heart $J$ 2006; 27 : 2763-2774

9. Duits AA, Duivenvoorden HJ, Boeke S, et al. A structural modeling analysis of anxiety and depression in patients undergoing coronary artery bypass graft surgery: a model generating approach. J Psychosomatic Research 1999; 46: 187-200.

10. Blumenthal JA, Lett HS, Babyak MA, et al. Depression as a risk factor for mortality after coronary artery bypass surgery. Lancet 2003; 362: 604-609.

11. Peterson JC, Charlson ME, Williams-Russo P, et al. New postoperative symptoms and long-term cardiac outcomes after coronary artery bypass surgery. Am J Geriatr Psychiatry 2002; 10: 192-198.

12. Pignay-Demaria V, Lesperance F, Demaria RG, FrasureSmith N, Perrault LP. Depression and anxiety and outcomes of coronary artery bypass surgery. Ann Thorac Surg 2003; 75: 314-321.

13. Connerney I, Shapiro PA, McLaughlin JS, Bagiella E, Sloan RP. Relation between depression after coronary artery by pass surgery and 12-month outcome: a prospective study. Lancet 2001; 358: 1766-1771.
14. Levin A. Depression, heart disease: links remain elusive. Psychiatr News 2005; 5: 33-41.

15. Borowicz JR, Royall R, Grega M, Selnes O, Lyketsos C, Mckhann G. Depression and cardiac morbility 5 years after coronary artery bypass surgery. Psychosomatics 2002; 43: 464-471.

16. Frasure Smith N, Lespérance F. Reflections on depression as a cardiac risk factor. Psychosom Med 2005; 67 Suppl 1: S19-25.

17. Hathaway SR, McKinley JC. MMPI-2. Minnesota Multiphasic Personality Inventory-2. Manuale. Firenze: Ed. Organizzazioni Speciali; 1987.

18. Sanavio S, Bertolotti G, Michielin P, Vidotto G, Zotti AM. CBA-2.0. Cognitive Behavioural Assessment 2.0, scale primarie. Firenze: Ed. Organizzazioni Speciali; 1987.

19. Hamilton M. A rating scale for depression. J Neurol Neurosurg Psychiatry 1960; 23: 56-62.

20. Beck AT, Steer RA. Beck Depression Inventory Manual. San Antonio TX, The Psychological Corporation, 1993.

21. Zigmond AS, Snaith RP. The Hospital Anxiety and Depression Scale. Acta Psychiatrica Scand 1983; 67: 361-370.

22. Radloff LS. The CES-D scale: a self-report depression scale for research in the general population. Appl Psychol Mes 1977; 3: 385-340.

23. Kop WJ, Ader DN. Assessment and treatment of depression in coronary artery disease patients. It Heart $J$ 2001; 2: 890-894.

24. Denollet J. Biobehavioral research on coronary heart disease: where is the person? J Behav Med 1993 Apr; 16(2):115-141.

25. Ragland DR and Brand RJ. Type A behavior and mortality from coronary heart disease. $N$ Engl J Med 1988 Jan $14 ; 318(2) 65-69$

26. Con AH, Linden W, Thompson JM, Ignaszewski A. The psychology of men and women recovering from coronary artery bypass surgery. J Cardiopulmorary Rehabil 1999; 19: $152-161$.

27. Rymaszewka J, Kiejna A, Hadrys T. Depression and anxiety in coronary bypass grafting patients. European Psychiatry 2003; 18: 155-160.

28. Vingerhoets G. Perioperative anxiety and depression in open-heart surgery. Psychosomatics 1998; 39: 30-37.

29. Cassano GB, Cancheri P. Trattato italiano di Psichiatria. Milano: Ed. Masson; 1993. pp. 1562-1577.

30. Pirraglia PA, Peterson JC, Williams-Russo P. Gorkin L. Charlson ME. Depressive symptomatology in coronary artery bypass graft surgery patients. Int J Geriatr Psychiatry 1999; 14: 668-680.

31. Boyle SH, Williams RB, Mark DB, et al. Hostility as a predictor of survival in patients with coronary artery disease. Psychosomatic Med 2004; 66: 629-632. 